\title{
UTILIZAÇÃO DAS FERRAMENTAS DE TECNOLOGIAS DIGITAIS DA INFORMAÇÃO E COMUNICAÇÃO PELO PROFESSOR NO ENSINO SUPERIOR
}

\author{
USE OF DIGITAL INFORMATION AND COMMUNICATION TECHNOLOGY \\ TOOLS BY TEACHERS IN HIGHER EDUCATION
}

\author{
Wagner Xantre Tagarro \\ Professor na Faculdade São José. Professor no Centro Universitário Carioca. Especialista em \\ Desenvolvimento Java. \\ https://orcid.org/0000-0002-8925-954X
}

Alexander de Araújo Lima

Professor no Centro Universitário Celso Lisboa. MBA em Gestão Financeira, Auditoria e Controladoria. https://orcid.org/0000-0002-6998-1324

Joaquim José Rodrigues da Fonseca

Professor na Universidade Iguaçu. MBA em Logística empresarial.

https://orcid.org/0000-0002-5826-3597

Ricardo Stavrakakis

Coordenador de segmento - ensino médio - Colégio Maria Raythe. Especialista em educação ambiental. https://orcid.org/0000-0001-5577-9806

\begin{abstract}
Alessandro Jatobá
Analista de Gestão em Saúde no Centro de Estudos Estratégicos da FIOCRUZ. Professor no Centro Universitário Carioca. Doutor em Engenharia de Produção COPPE/UFRJ

https://orcid.org/0000-0002-7059-6546

Victor Gonçalves Gloria Freitas

CEO na AresVR. Professor no Centro Universitário Carioca. Doutor em Engenharia Nuclear pela COPPE/UFRJ. Mestre em Engenharia de Reatores pelo Instituto de Engenharia Nuclear. http://orcid.org/0000-0002-0154-606X
\end{abstract}

Data de submissão: $24 / 10 / 2019$

Data de aprovação: 14/12/2019

\section{RESUMO}

Este artigo investiga a relação dos professores com as Tecnologias Digitais da Informação e Comunicação (TDICs) na educação e o uso das ferramentas adequadas a serem aplicados em cursos a distância e presenciais, cujo objeto de investigação são as tecnologias da informação e comunicação como ferramenta no processo ensinoaprendizagem no ensino a distância e presencial, sempre visando à melhor capacitação profissional do professor e do tutor. Sobre o processo de mediação e aprendizagem, o trabalho está embasado nas análises do uso das tecnologias digitais na utilização por parte dos professores no ensino superior. A metodologia fundamenta-se na pesquisa por meio de formulário eletrônico como instrumento de coleta de dados. Os resultados apontaram problemas enfrentados no conhecimento das ferramentas de TDICs aplicadas na educação superior. Conclui-se que em função das inovações tecnológicas, os professores encontram-se desatualizados, sugerindo-se capacitação mais frequente na 
área das inovações tecnológicas, dando ao professor o direito de acompanhar as constantes mudanças que acontecem na educação digital, mas também por sua proposta inicial de permanecer como um centro de oferta de cursos a distância na instituição pesquisada. Portanto, essa pesquisa busca uma melhoria contínua dos processos educacionais aliados aos tecnológicos, para contribuir nas sequências pedagógicas e da aprendizagem do discente, docente e instituição de ensino.

Palavras-chave: Pesquisa. Educação Superior. Capacitação.

\section{ABSTRACT}

This paper presents an investigation into the relationship between teachers and Digital Information and Communication Technologies (TDICs) in education and the use of appropriate tools to be applied in distance and face-to-face courses, whose object of investigation is information and communication technologies. Communication as a tool in the teaching-learning process in distance and classroom teaching, always aiming at the best professional qualification for the teacher and tutor. About the process of mediation and learning, were based on the analysis of the use of digital technologies in the use by teachers in higher education. The methodology is based on research through electronic form as a data collection instrument. The results pointed to problems faced in the knowledge of TDIC's tools applied to higher education. It is concluded that due to technological innovations, teachers are outdated, being suggested skills in the area of technological innovation more often, giving the teacher the right to follow the constant changes that happen in digital education, but also by his proposal. remain as a center for distance learning courses at the institution surveyed. Therefore, this research seeks a continuous improvement of educational processes combined with technological processes, to contribute to the pedagogical and learning sequences of the student, teacher and educational institution.

Keywords: Research. Higher education. Training.

\section{INTRODUÇÃO}

Estamos vivendo transformações em sociedade e uma destas se dá principalmente devido às tecnologias digitais de informação e comunicação TDICs e as mudanças influenciam fortemente o processo de como pensamos, de como sabemos, de como aprendemos. O ensino-aprendizagem precisa se adequar às novas práticas, métodos e competências necessárias às relações com os estudantes e às necessidades e/ou demandas do mercado e das novas configurações sociais. As relações sociais mudaram devido às novas tecnologias de informação e comunicação e neste viés as instituições vivem um processo de mudança pragmática e, em especial, a educação e o ensino nos diversos níveis (BEHRENS, 2005).

As tecnologias digitais, cada vez mais presentes na vida de cada um, têm provocado mudanças nas percepções que temos do mundo e nas maneiras de interagirmos com as pessoas, nas relações políticas, econômicas e sociais. A nova geração conectada prefere o papel de protagonista ao de mero espectador do processo. É preciso que os cursos estejam de acordo com essa nova necessidade.

Nesse cenário, há uma recursividade entre educação presencial e educação à distância, pois se influenciam reciprocamente e os métodos e metodologias usados se comunicam, se atualizam mutuamente, o que provoca transformação dos métodos de ensino, bem como uma mudança na organização do trabalho, pois as tecnologias são 
meios e mídias muito importantes na educação, trazendo contribuições importantes na melhoria dos sistemas.

Outro aspecto muito importante é frisar que evoluímos muito em áreas da educação superior, e por exemplo, se pensarmos nas tecnologias de informação e comunicação nesta modalidade, hoje oferecem-se oportunidades diversificadas de formação, organizáveis de modo flexível, de acordo com as possibilidades do aluno, podendo ser com "atividades presenciais, mas sem professor, de interação entre estudantes, que trabalharão em equipe de modo cooperativo". (BELLONI, 2001, p. 6-7). São transformações que somente são possíveis devido às novas tecnologias de informação. Dentro desse escopo, é preciso que toda esta grandeza midiática disponibilizada na educação possa ser acessada de forma planejada, para se construir uma educação integral até onde se puder ir com esta proposta metodológica.

Nos últimos anos se observa uma tendência a uma maior utilização das tecnologias digitais de informação e comunicação na educação a distância e no ensino presencial; no entanto, a infraestrutura apresentada ainda é insuficiente por situações financeiras relacionadas ao atual cenário econômico vivenciado pelo Brasil. Momo et al. (2017) identificam que as TDICs estão presentes nas práticas docentes e possuem um papel de suportar e mediar as atividades realizadas por esses profissionais e que o uso das tecnologias por eles é influenciado por questões institucionais e pelo conhecimento do professor sobre elas.

Portanto, a forma como os professores as utiliza, os objetivos a serem alcançados e o que pretendem vão colaborar para que se consiga identificar as dificuldades ou facilidades para a tomada de decisão quanto ao uso das ferramentas digitais da tecnologia da comunicação e informação na aplicação no ensino a distância.

Freitas (2015) afirma que o uso da Internet, seja por meio dos celulares, smartphones ou de recursos como Facebook, Ipad, Ipod, tablets e redes sociais, cria ações entre os indivíduos e tais atividades acionam novos processos cognitivos que, por sua vez, organizam novas aprendizagens aos estudantes.

Essas novas formas de aprendizagem fornecem um auxílio externo à cognição, promovem mudanças nas habilidades cognitivas requeridas para certas atividades e permitem uma simplificação do mundo ao tornarem disponíveis e utilizáveis as informações relevantes para os indivíduos. Todos esses processos implicam em uma série de transformações, e as ferramentas tecnológicas podem estimular os campos colaborativos do pensamento e criar novas estruturas de representação, conhecimento, significação, simplificando e ao mesmo tempo dando asas à complexidade, produzindo grandes transformações em nossas formas de pensar, ser e saber, mudando nossa relação com o mundo.

O problema a ser pesquisado tem como ponto de partida o encontro mágico entre educação e tecnologia e neste ponto nota-se: a existência de instituições com uma educação conservadora; outras, em que o trabalho perde-se no conjunto de ações pedagógicas deslocadas de um plano conjunto; outras ainda que não conseguem traduzir todo o esforço pessoal em ações, por falta de sinergia coletiva. Casos como esses indicam que embora existam ferramentas tecnológicas digitais da informação e comunicação em condições para orientar um ensino de qualidade à distância, estes se tornam ineficazes por falta de ações articuladas e conjuntas.

A presente pesquisa tem como objetivo geral propiciar reflexões acerca da utilização das tecnologias da informação e comunicação como ferramenta no processo ensino-aprendizagem no ensino superior, sempre visando a uma melhor capacitação 
profissional do professor e do tutor. Os objetivos específicos estão assim relacionados: Demonstrar as ferramentas tecnológicas utilizadas pelo professor no ensino a distância e no ensino presencial; Levantar quais as ferramentas da TDICs não estão sendo utilizadas no processo de ensino-aprendizagem; Identificar as tecnologias no processo de ensinoaprendizagem online; Verificar a aplicação das TDICs pelo professor no ensino a distância e no ensino presencial.

\section{REFERENCIAL TEÓRICO}

\subsection{Tecnologia no ensino a distância}

As práticas envolvendo docentes e discentes exigem "[...] uma programação que pode ser refeita durante o processo permanente de sua avaliação. Praticar implica programar e avaliar a prática. E a prática de programar, que se alonga na de avaliar a prática, é uma prática teórica". (FREIRE, 2001a, p. 109).

Os novos meios de comunicação dão acesso a conteúdos e informações, abrem as portas de bibliotecas, livros, mentes e é preciso entender que este mundo digital é parte integrante da sociedade - e que todos estamos inseridos, mesmo quando excluídos, a lacuna está ali, vazia. A nova geração faz parte deste novo contexto. A tecnologia desperta o interesse e aproxima aqueles que estão inseridos.

Todo esquema de assimilação é construído e toda abordagem à realidade supõe um esquema de assimilação. Quando a mente assimila, ela incorpora a realidade e seus esquemas de ação, impondo-se ao meio. Muitas vezes, os esquemas de ação da pessoa não conseguem assimilar determinada situação. Neste caso, a mente desiste ou se modifica. Quando a mente se modifica acontece o que Piaget chama de acomodação. As acomodações levam à construção de novos esquemas de assimilação, promovendo, com isso, o desenvolvimento cognitivo. (OSTERMANN; CAVALCANTI, 2010, p. 22)

$\mathrm{Na}$ revista EDaPECI - SE, o artigo "Metodologias ativas aplicadas à educação a distância: revisão de literatura", de autoria de Fonseca e Mattar Neto (2017), mostra que a adoção de metodologias ativas promove melhorias consideráveis no processo de ensinoaprendizagem. Mas, para isso ocorrer, todos os envolvidos nesse contexto devem compreender a significância do seu real sentido e acreditar no seu potencial de aprendizagem.

Existem algumas dificuldades que devem ser consideradas no uso das TDICs. As próprias características dessas tecnologias podem configurar entraves. Vejamos um exemplo: um vídeo em formato digital ocupa certo "espaço" no computador, isto é, um número de bytes para ser armazenado. Dependendo do tamanho desse vídeo, será inviável transmiti-lo para os alunos utilizando a internet, se esses alunos contarem apenas com uma banda de transmissão internet de baixa velocidade. Caso o professor escolha essa prática, pode contribuir mais negativamente do que positivamente para o processo de ensino, porque os alunos podem ficar desmotivados, esperando que o vídeo seja carregado.

Percebemos assim que, embora as ferramentas TDICs ofereçam oportunidades para uso da $\mathrm{EaD}$, é preciso cuidado na realização do planejamento. Os próprios professores carecem de formação adequada para trabalharem de forma efetiva na utilização dela. É indispensável que os professores compreendam que as TDICs representam um novo paradigma para a educação. Não se deve continuar a usar velhos 
métodos com novas ferramentas. Devemos estar preparados para pensar em novos métodos com novas ferramentas.

Trabalhar com EAD requer profissionais e atores sensíveis e dispostos à inovação, porque atuam em um setor de transitoriedade, no qual a única certeza é a permanente mudança, cujas influências chegam pelos diferentes idiomas dos países que produzem conhecimento exponencial para a área (FORMIGA, 2009).

Para endossar o exposto, Silva (2003) enumera cinco habilidades que, segundo ele, são essenciais aos professores que querem transformar sua sala de aula, seja ela presencial ou a distância, em espaços interativos:

1. abrir espaço para a participação-intervenção dos alunos, compreendendo que mais que dizer sim ou não, que responder a questões prontas, participar significa atuar na construção do conhecimento e da comunicação; 2. permitir a bidirecionalidade da comunicação, sabendo que é na ação conjunta de professores e alunos que a aprendizagem acontece; 3. disponibilizar múltiplas redes articulatórias, permitindo ao receptor ampliar suas conexões e significações; 4. engendrar a cooperação, valorizar a cocriação, o trabalho em equipe; 5 . suscitar a expressão e a confrontação das subjetividades, pois é preciso lidar com as diferenças para que ocorra construção da tolerância e da democracia.

Na percepção de Tarcia e Costa (2010, p. 152),

A tecnologia responde constantemente às necessidades da sociedade contemporânea e, por esse motivo, as inovações surgem de maneira acelerada no mundo atual. Nesse contexto de renovação constante, aprender a lidar com o novo representa desafio interessante, porque somos chamados, a todo momento, a aprender mais e conhecer 0 diferente. A prática docente também vive essa situação: diante das novas necessidades que a educação impõe e das dificuldades enfrentadas pelo professor, é importante buscar as alternativas e os recursos.

Conforme destacaram Tarcia e Costa (2010, p. 4), a curiosidade pelo saber é uma das competências necessárias ao professor, principalmente daqueles ligados aos cursos de educação a distância. Porém as autoras alertam que:

O professor só mudará sua prática se estiver disposto a refletir de maneira sistemática sobre ela. [...] Por isso, defendemos a atitude crítica e reflexiva, de busca de novas alternativas para tornar a prática educativa a distância alinhada com a atualidade, com o domínio dos recursos tecnológicos não apenas para propiciar o acesso à informação, mas também, e sobretudo, para propiciar relacionamentos com os estudantes, para criar redes de comunicação que os conduzam à construção coletiva de conhecimento, de uma identidade de grupo participativo e ativo na sociedade, reinventando-se constantemente.

Segundo Kenski (2003), o maior problema verificado na relação entre os docentes e a tecnologia é a falta de informação adequada para que eles possam incorporar esses recursos.

Nesse contexto, os professores são vistos como elementos partícipes de tal relação desarmônica, uma vez que muitos ainda atuam com uma metodologia típica do século XX, exercendo papel de únicos detentores do conhecimento. Desse modo, prescinde-se de uma educação lúdica, resultando em uma realidade atual na qual o educando, na ausência de interação dentro do ambiente escolar, prefere buscar a 
informação na internet, deixando, por sua vez, de ter a mediação valorosa do professor nesse processo.

Segundo Moran (2009), as escolas devem repensar seus objetivos para que haja uma flexibilização no ensino, sem necessariamente perder em qualidade. Ele afirma que, em breve, o presencial vai se tornar um luxo, e os momentos a distância facilitarão o acesso de outras pessoas ao curso, e o segredo está em unir o melhor do presencial com o melhor do virtual.

No Congresso Internacional de Educação e Tecnologias, em 2018, realizou-se o encontro de pesquisadores em educação a distância. Na ocasião, foi apresentado o tema "Tecnologias da informação e comunicação no ensino superior e seus benefícios". Neste trabalho, ficou evidenciado que a formação contínua dos professores é fundamental para que ele esteja preparado para lidar com as ferramentas TDICs que são positivas para o processo de ensino e aprendizagem".

Segundo Lima (2006), não basta que os professores ensinem os alunos a aprender; eles têm que os ensinar também a pesquisar e a relacionar entre si diversas informações, despertando neles o espírito crítico, pois a quantidade de informações que atualmente circula nas redes de informações é imensa, tornou-se um pré-requisito orientar-se em meio aos saberes.

Assim, teríamos um novo processo de ensino-aprendizagem, numa escola que atenderia aos interesses dos estudantes, suas reais necessidades, colocando-os na condição de protagonistas desta relação e contribuindo para elaboração do seu próprio conhecimento.

Segundo Vygotsky (1984), a interação social se torna importante para que o professor modele a solução apropriada, estruture seu apoio para o aluno encontrar a solução, ao mesmo tempo, ele, o professor, monitora o progresso do aluno. Assim, o crescimento e aquisição de conhecimentos cognitivos individuais são facilitados.

Considerando que o conhecimento é adquirido através de uma interação mútua, cabe aos professores e à escola utilizar as ferramentas disponíveis para executar uma aula mais interessante e atraente, assim colaborando com o aprendizado do discente.

Vygostky (2003) argumenta que o ambiente devidamente preparado é fundamental para que o professor exerça seu papel incomensuravelmente maior que é promover a interação entre os participantes do meio pedagógico. Para Gadotti (2000, p. 8)

o conhecimento é o grande capital da humanidade. Não é apenas o capital da transnacional que precisa dele para a inovação tecnológica. Ele é básico para a sobrevivência de todos e, por isso, não deve ser vendido ou comprado, mas sim disponibilizado a todos.

Deve-se, também, considerar que a grande tendência no século XXI é o ensino híbrido, no qual ocorre uma mistura envolvendo o ensino presencial e as propostas de ensino a distância. Neste, através da ocorrência de colaboração, interação e envolvimento com as tecnologias digitais ocorre uma mistura metodológica que envolve a ação do professor em situações de ensino e a ação dos estudantes em situações de aprendizagem com o uso das TDICs.

Corroborando a situação descrita, Aretio (2002, p. 144 -148) afirma que é fundamental ao docente de EaD:

- Planejar e organizar cuidadosamente a informação e o contato com seus alunos, seja presencial ou virtualmente. Todas as tarefas devem ser feitas com antecipação: o quê, como e quando ensinar, sugerir, 
orientar, motivar, etc. Também é conveniente apresentar quem é o tutor, o professor, o coordenador do curso e quais são suas prioridades e modelos de ensino-aprendizagem.

- Motivar para iniciar e manter o interesse em aprender: o aluno adulto estuda porque quer fazer isso, então bastará convencê-lo da utilidade que determinados processos de aprendizagem podem ter, relacioná-los com suas necessidades e interesses. Podem ser sugeridos tempos e fases para o estudo, por partes, do material. Para manter a motivação, o aluno deverá ser informado frequentemente de seus progressos de aprendizagem.

- Explicitar os objetivos que se pretende alcançar: os objetivos devem ser claramente percebidos pelos alunos e devem atender à resolução de alguns dos seus problemas profissionais, pessoais ou sociais. Essa é a melhor fonte de motivação.

- Apresentar conteúdos significativos e funcionais, que sejam apoiados naquilo que o aluno já sabe ou experimentou, que partam do concreto, com sentido próprio e que sirvam objetivamente para resolver problemas relevantes tanto pessoais como sociais. Os estudantes devem visualizar com clareza quais são os conceitos e ideias-chave. No processo de mediação pedagógica deve-se oferecer a eles toda informação e orientação necessárias ao uso efetivo de todos os recursos multimídia que a instituição, o programa ou o curso colocam à sua disposição.

- Solicitar a participação dos estudantes: o aluno adulto aprende melhor quando sabe que é protagonista do próprio aprender. Corresponsabilidade e participação são táticas necessárias para que se façam progressos na aprendizagem. O grau de aprendizagem vai depender da dedicação, esforço e compromisso postos em cena pelo adulto. Daí a necessidade de sua participação ativa e democrática, incluída no planejamento da ação tutorial.

- Ativar respostas e fomentar uma aprendizagem ativa e interativa: a aprendizagem ativa exige que se impliquem os estudantes em seu próprio processo de formação. O uso de ferramentas que exijam uma interatividade elevada entre professor e estudantes e estes entre si é uma importante tarefa que deve ser impulsionada pela mediação pedagógica.

- Incentivar a autoformação sem esquecer dos apoios motivadores de aprendizagem para que sejam alcançadas altas metas. A motivação não pode ser oferecida apenas na etapa inicial do curso, devendo ser mantida durante todo o processo. O tutor tem a responsabilidade de fomentar a capacidade de desenvolvimento e de autoaprendizagem dos alunos. O mediador pedagógico deve intervir de maneira estimulante e manifestar seus conhecimentos, sensibilidades, oferecer ajuda. Isso porque se o aluno sentir que está com muita dificuldade para alcançar seus objetivos, terá seu interesse diminuído, a menos que o tutor mantenha o ritmo de incentivos e apoio, respeitando o ritmo do aluno e seu modo de aprender. O sucesso da aprendizagem resultará também da crença do aluno de que seus objetivos são alcançáveis.

- Incentivar o trabalho colaborativo em grupos de aprendizagem: apesar das vantagens do trabalho independente, um professor não pode ignorar a potencialidade de ensino de trabalhos e discussões em grupos, sejam eles virtuais ou presenciais.

- Facilitar a realimentação. A realimentação ou o feedback sempre se convertem em uma fonte de reforço. 
- O feedback deverá ser dado ao aluno com a máxima rapidez. Há que se tomar muito cuidado na devolução de provas de avaliação e trabalhos que todo curso a distância deve contemplar. $\mathrm{E}$ essas repostas têm de ser completas e esclarecedoras, mantendo um tom pessoal e motivador.

- Reforçar o autoconceito e respeitar a diversidade do grupo. É fundamental respeitar os medos que muitos adultos têm dos processos de formação e lembrar que a atenção pedagógica não diminui a pessoa nem por sua idade, nem pelo nível de seus conhecimentos ou dificuldades de estudo. Os erros cometidos por adultos se refletem em sua autoestima e, portanto, é fundamental um tratamento cordial e próximo, com muito respeito pelas dificuldades e ritmos de aprendizagem de cada um.

- Promover a transferência das aprendizagens. Não pode haver pressa no processo de aprendizagem: ela deve acontecer mediante um encadeamento, em um processo lógico e pausado. É necessária a relação dos novos conteúdos com os anteriores e com as experiências pessoais dos alunos. Conduzida da maneira coerente, novas ideias poderão se constituir como base para futuras aprendizagens. O tutor deverá sugerir, sempre que possível, a aplicação dos conhecimentos em diferentes situações visando facilitar a retenção e a lembrança dos saberes e competências que vão sendo adquiridos durante o processo.

- Avaliar formativamente o progresso. É por meio da avaliação formativa que 0 aluno terá condições de julgar sua situação e suas necessidades educacionais, tendo a oportunidade de reconduzir seu esforço, de se aprimorar cada vez mais.

Existem mudanças nos modos de produção e construção do conhecimento a partir da introdução das tecnologias digitais no cenário educacional; existem novas maneiras de acessar a informação, assim como existem novas formas de se relacionar com o mundo. Com isso, dizemos de forma assertiva que necessitamos da tecnologia em nossos espaços educacionais e na universidade.

\section{METODOLOGIA}

Realizou-se uma pesquisa com professores de instituições particulares de ensino superior a distância por meio de um questionário estruturado e disponibilizado no Google Forms, com o intuito de verificar quais são as dificuldades dos docentes na utilização das ferramentas de TDICs.

Com isso, se buscará diagnosticar o nível de uso das TDICs entre os docentes de instituições de nível superior particular.

A pesquisa adotada será de natureza descritiva com abordagem quantitativa.

\subsection{Coleta de dados}

Professores que trabalham em instituições de ensino superior na cidade do Rio de Janeiro são o objeto de estudo desta pesquisa. Foram coletadas as percepções de docentes de instituições, cujas informações estão em poder e guarda dos autores deste artigo.

O questionário foi disponibilizado em grupos de WhatsApp dos docentes das instituições de ensino superior e enviado também por meio de e-mail institucional para cada um dos docentes. 
A aplicação ocorreu em instituições de ensino superior em razão de haver um forte crescimento da demanda em busca de ensino a distância. Com isso, a responsabilidade do docente em saber lidar com as ferramentas digitais aumentou consideravelmente.

Como fundamentação desta aplicação cita-se o artigo publicado recentemente: "O professor frente as novas tecnologias e as implicações no trabalho docente", de autoria de Silva (2016), mostrou que o papel do professor não fica desmerecido quando entendido como mediador do processo de ensino, seja em atividades presenciais ou a distância, não sendo apenas um provedor de informações.

O questionário foi validado pelos coordenadores das instituições pesquisadas e, em seguida, encaminhado para os grupos e e-mails dos professores.

Abordaram-se os seguintes tópicos nesta aplicação para os docentes:

- Frequência com que utiliza os recursos digitais para se comunicar com os estudantes.

- Frequência com que utiliza os recursos digitais para compartilhar material das aulas com os estudantes.

- Frequência com que utiliza os recursos digitais para desenvolver atividades em sala de aula com os estudantes.

- Durante as aulas, a frequência com que os estudantes, por iniciativa própria, usam computador, tablet ou celular.

- Durante as aulas, a frequência com que os estudantes, orientados pelo professor, usam computador, tablet ou celular.

- As percepções do professor com relação ao uso de tecnologias digitais no ensino superior.

- Frequência com que utiliza ferramentas de TDICs nas aulas.

- Frequência com que utiliza estratégias didáticas nas aulas.

- As percepções sobre a inovação das práticas com uso de tecnologias.

- Opinar sobre o significado da inovação das práticas pedagógicas.

- Indicar as ações consideradas inovadoras.

- Descrever uma atividade considerada inovadora com uso de tecnologias digitais.

O questionário possui 12 itens, que funcionarão como um elemento norteador para medir o capital tecnológico dos docentes de forma que se busquem novas práticas, corroborando em processos de formação e acompanhamento que garantam uma adequada integração na formação profissional dos docentes, transformando-se em apoiador para alcançar a qualidade educativa.

\section{ANÁLISE E DISCUSSÃO DOS RESULTADOS}

Os resultados apresentados por esta pesquisa estão divididos em quatro aspectos básicos: frequência na utilização de tecnologias, percepções sobre o uso de tecnologias, ferramentas e estratégias didáticas, percepções sobre o uso de tecnologia e inovação e percepções sobre ações consideradas inovadoras.

Foram coletadas as percepções de docentes de 9 instituições de ensino superior na cidade do Rio de Janeiro por meio do preenchimento de formulário eletrônico. $\mathrm{O}$ 
formulário foi disseminado por e-mail e por grupos de WhatsApp com autorização dos gestores das respectivas instituições de ensino. Foram entrevistados 137 professores.

\subsection{Frequência na utilização de tecnologias}

Sobre a utilização de tecnologia em sala de aula por parte dos professores, perguntou-se sobre a frequência no uso de algumas ferramentas específicas para comunicação com os estudantes. As opções oferecidas foram e-mail, Facebook, Moodle e WhatsApp.

O e-mail é a ferramenta preferida pelos professores. 35,04\% declararam sempre usar a ferramenta e outros $29,20 \%$ disseram fazer uso frequente. O WhatsApp é o segundo na preferência dos docentes, com $27,74 \%$ indicando usar sempre o recurso e $21,90 \%$ declarando uso frequente.

O Facebook e o Moodle são os menos populares entre os educadores, sendo o primeiro rejeitado por $46,2 \%$ dos entrevistados, enquanto o Moodle não é utilizado por $39,42 \%$ dos professores.

Esta primeira abordagem indica uma preferência dividida entre meios mais formais como o e-mail e mais eficazes e rápidos como WhatsApp. A exposição de redes sociais como o Facebook e uma possível dificuldade de exploração dos recursos do Moodle podem ser os motivos que repelem os professores ao uso destas tecnologias.

Figura 1 - Utilização de ferramentas digitais para comunicação

\section{Utilização de Ferramentas Digitais para Comunicação}

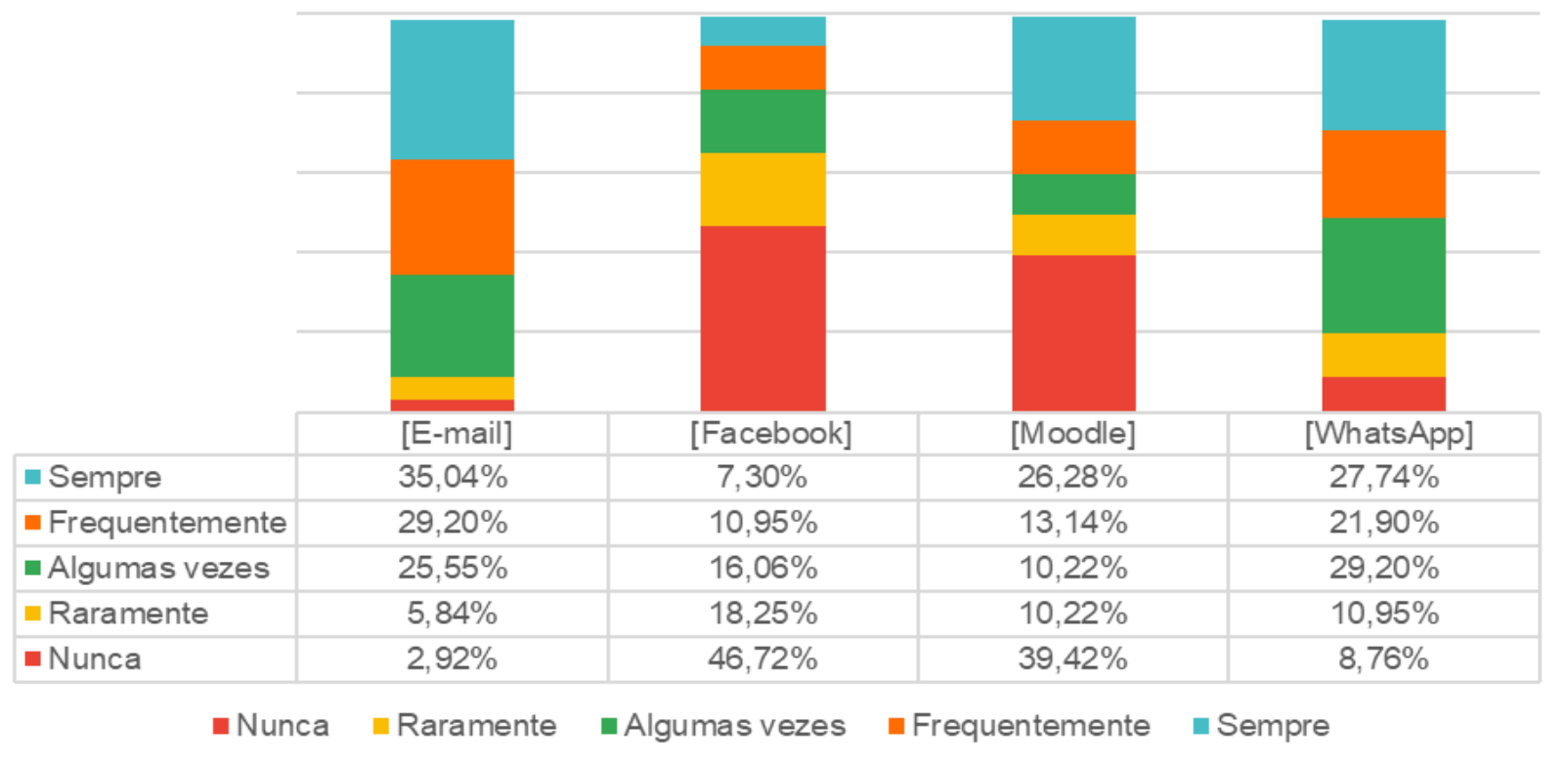

Fonte: Elaborado pelos autores (2019).

Quando perguntados sobre qual tecnologia é utilizada para compartilhar o material das aulas com os estudantes, os resultados corroboram a análise anterior. Como opções de tecnologia para compartilhamento de materiais, foram elencados o e-mail, Facebook, Google Drive, WhatsApp, Dropbox, Blogs e Sites.

Mais uma vez, o e-mail é o meio preferido dos professores; $24,63 \%$ declararam usar sempre, e outros $23,12 \%$ disseram fazer uso frequente do recurso. O WhatsApp é sempre usado por $18,75 \%$ dos respondentes e frequentemente usado por $14,06 \%$. Dentre 
as ferramentas de armazenamento em nuvem, o Google Drive é o mais popular, sempre usado por $15,75 \%$ dos professores e frequentemente usado por outros $15,75 \%$.

Os maiores índices de rejeição são os blogs (81,10\%) e o Facebook (67,97\%). Dentre as ferramentas de armazenamento em nuvem, o Dropbox não é utilizado por $61,79 \%$.

Corroborando a pergunta anterior, os docentes preferem ferramentas mais usuais e práticas, como e-mail e WhatsApp. Mais uma vez o Facebook conta com alta rejeição, possivelmente por conta do perfil mais social desta rede.

Um indicador importante é a rejeição por blogs e sites, o que pode indicar uma falta de engajamento do docente em produzir seu próprio conteúdo e torná-lo público.

Figura 2 - Utilização de ferramentas digitais para compartilhamento de material

Utilização de Ferramentas Digitais para Compartilhamento de Material

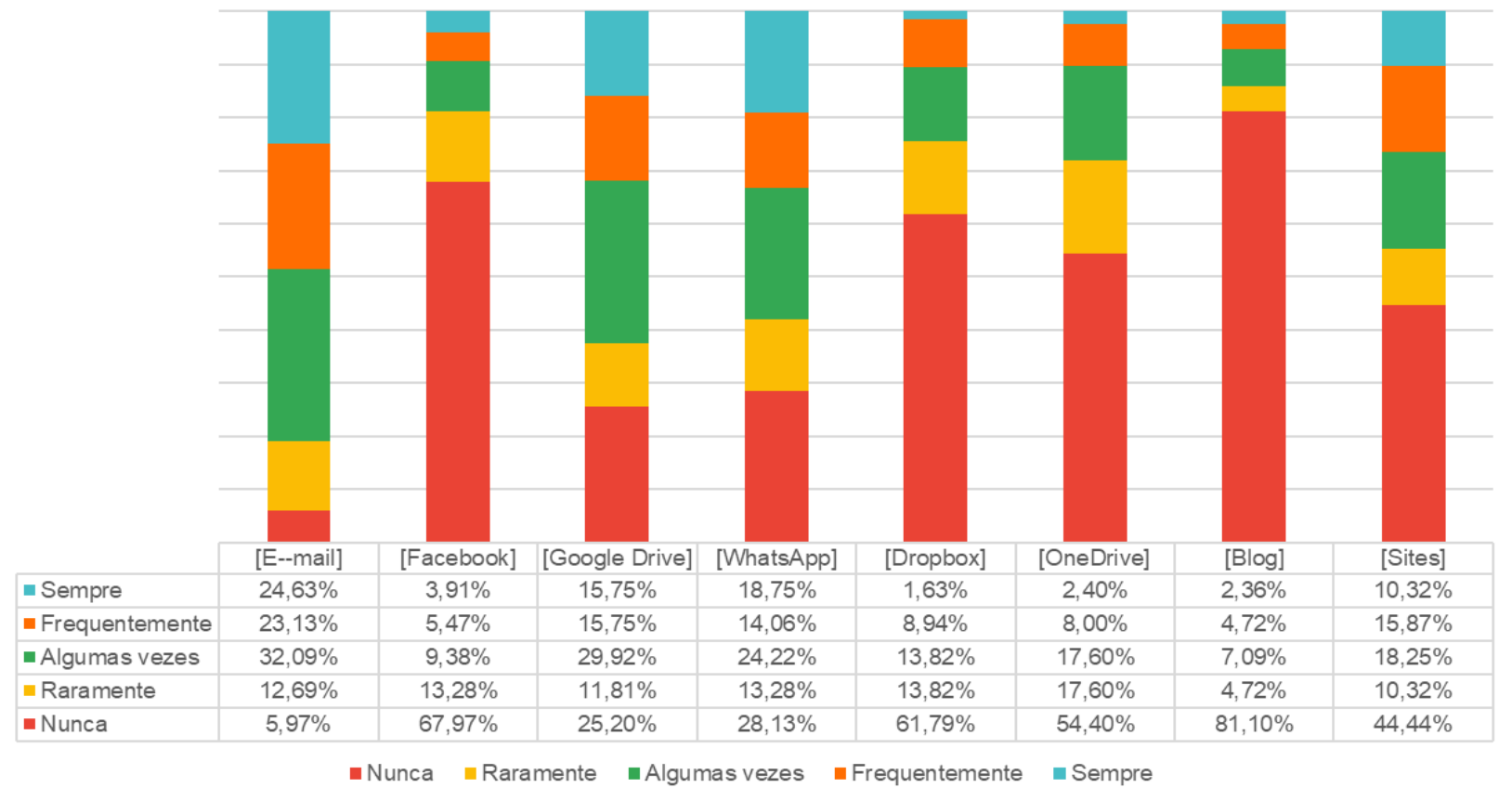

Fonte: Elaborado pelos autores (2019).

Dentre as tecnologias utilizadas para o desenvolvimento e criação das atividades praticadas em sala de aula, os recursos de editores de slides e textos são os preferidos. $46,15 \%$ dizem sempre usar o Powerpoint e $28,79 \%$ sempre usam editores de texto como o Word. $27,69 \%$ e $35,61 \%$ indicam o uso frequente de Powerpoint e Word, respectivamente.

Outro recurso com preferência significativa é o Moodle, sempre utilizado por $25 \%$ dos professores. Os demais recursos não apresentaram frequência de utilização significativa na pesquisa.

Os recursos utilizados eventualmente pelos professores são as ferramentas do Google para planilhas, criação de formulários e armazenamento de arquivos. Na mesma medida, está o WhatsApp; no entanto, este recurso conta com uma rejeição de $44,19 \%$ dos professores.

O Facebook, mais uma vez, aparece na lista de rejeição, com 67,74\% dos professores que afirmam nunca utilizar a ferramenta como parte de suas aulas. A rejeição 
maior, no entanto, é do aplicativo de criação de "linhas do tempo", Timetoast, com $85,60 \%$.

Pode-se inferir que, quanto à rejeição, há fatores distintos colaborando para este levantamento. O Facebook é uma ferramenta conhecida e, para os professores entrevistados, pouco adequada às atividades docentes. Outras são rejeitadas por desconhecimento da finalidade ou talvez por falta de habilidade na utilização.

Mais uma vez, os recursos preferidos são mais usuais e conhecidos, como os produtos do pacote office da Microsoft.

Figura 3 - Utilização de ferramentas digitais para compartilhamento de material

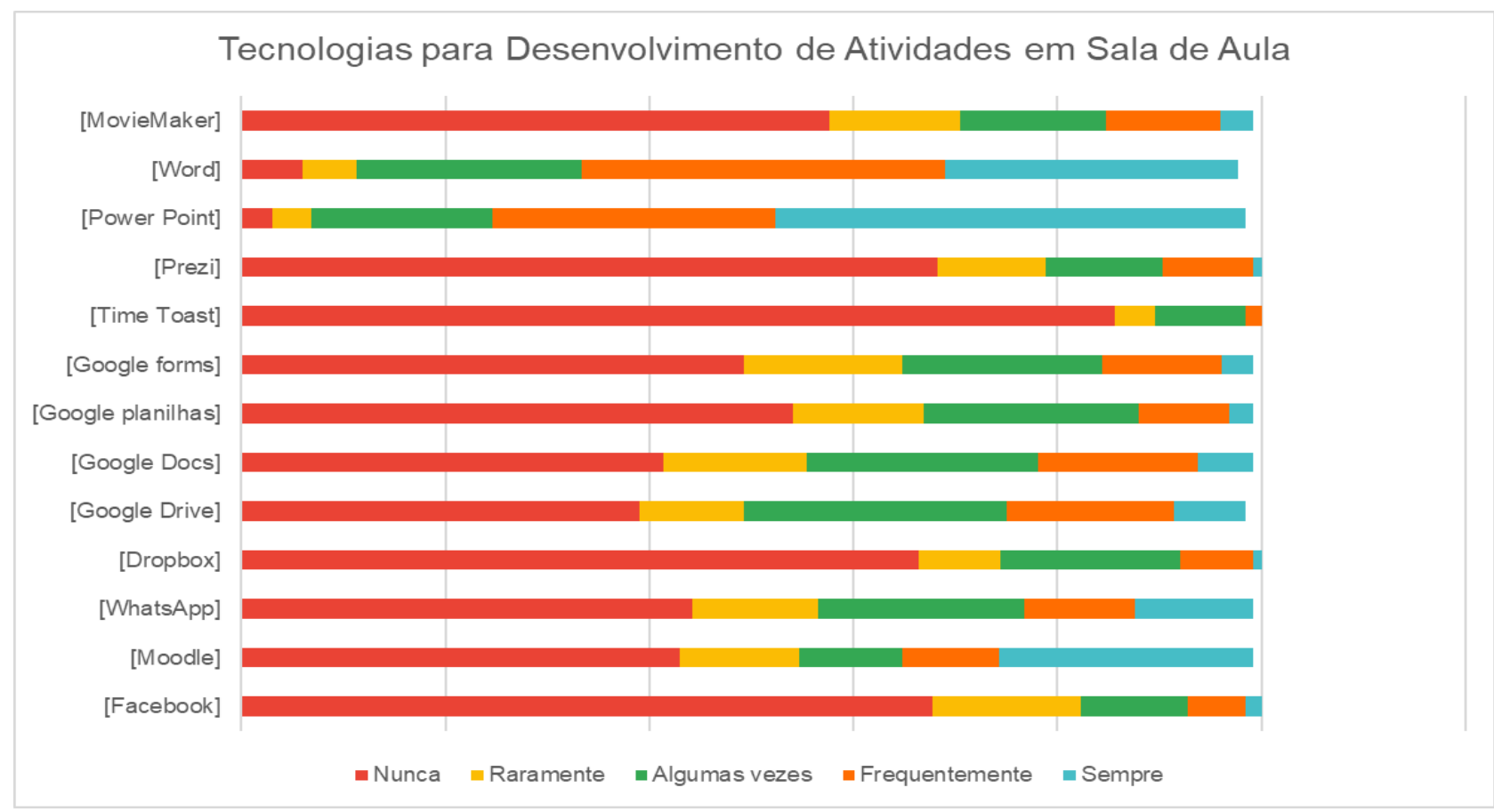

Fonte: Elaborado pelos autores (2019).

Pesquisou-se, também, a percepção dos professores quanto ao uso de aparelhos eletrônicos em sala de aula, sem que esta utilização derivasse de orientação ou pedido do professor. 
Figura 4 - Utilização de aparelhos eletrônicos pelos estudantes (uso espontâneo)

\section{Utilização de Aparelhos Eletrônicos pelos Estudantes}

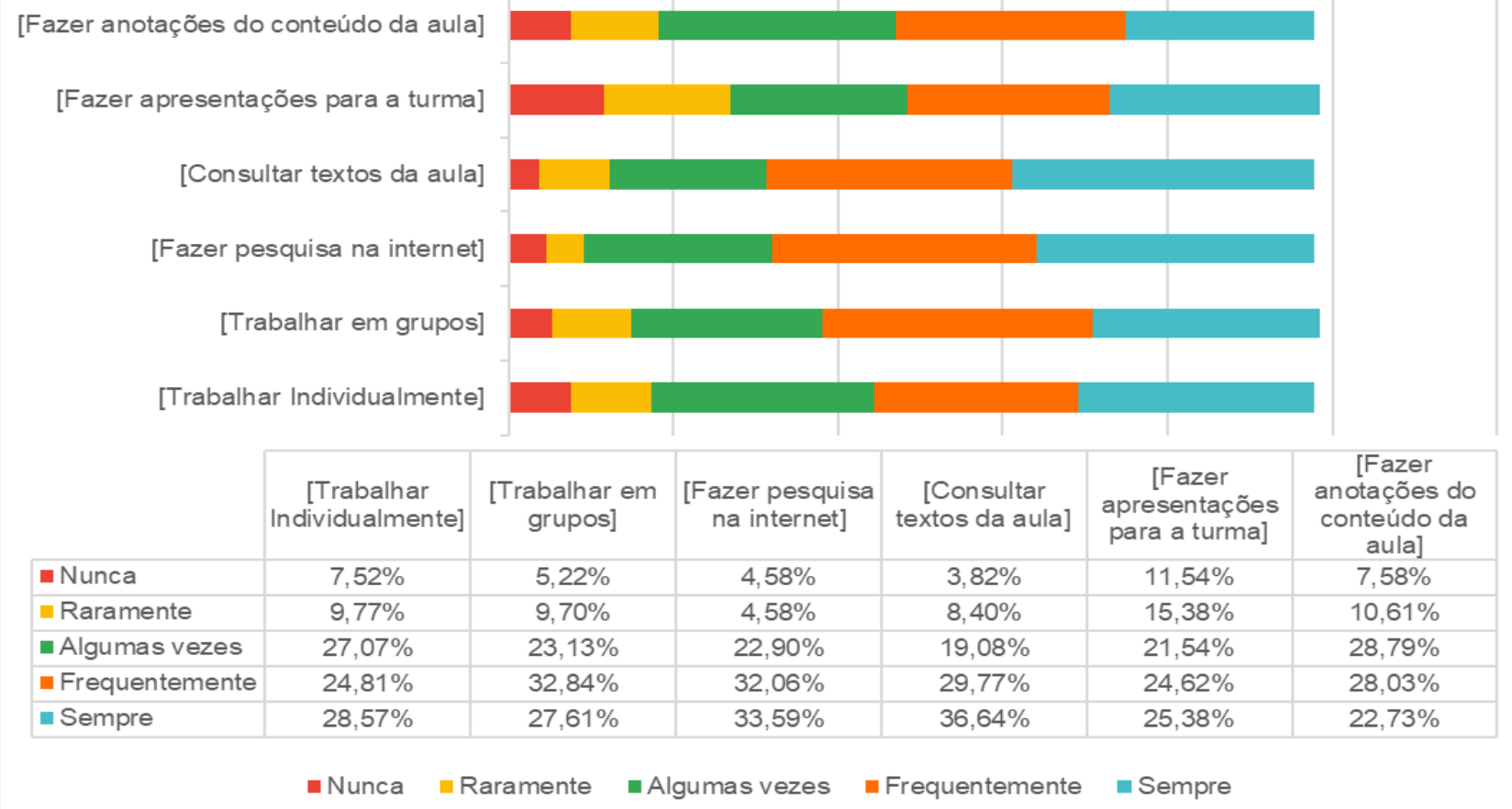

Fonte: Elaborado pelos autores (2019).

As atividades que sempre estimulam o estudante a fazer uso de aparelhos eletrônicos em sala de aula, de forma espontânea, sob a ótica do professor, é a consulta de textos relativos à aula $(36,64 \%)$ e a realização de pesquisas na internet $(33,59 \%)$. Ainda segundo os professores, os estudantes usam os recursos para desenvolver trabalhos em grupo ou individuais.

Destaca-se, entre as respostas a esta pergunta, o baixo índice da resposta "nunca", o que indica que entre os discentes, é massiva a utilização de aparelhos eletrônicos em sala de aula.

A mesma pergunta, sobre a utilização de aparelhos eletrônicos pelos estudantes, foi feita, desta vez, sobre esta percepção a partir do estímulo do professor, ou seja, em que ocasiões são sugeridos o uso desses equipamentos.

Observou-se um alinhamento deste resultado com o da pergunta anterior. 40,77\% e $38,64 \%$ dos professores disseram que sempre estimulam seus estudantes a usar os equipamentos para fazer pesquisas na internet e consultar os textos da aula, respectivamente. Alternativas que sempre contam com a recomendação do professor para uso dos aparelhos são os trabalhos em grupo e individuais. Aproximadamente $12 \%$ dos entrevistados nunca estimularam seus estudantes ao uso dos aparelhos eletrônicos para fazer anotações em sala de aula ou fazer apresentações para a turma.

Esta proximidade entre as respostas a ambas as perguntas sobre o uso dos aparelhos eletrônicos, de forma espontânea por parte dos estudantes e sob a orientação do professor, pode indicar que os estudantes estão condicionados ao estímulo do professor, ou que o professor tentou ratificar essa condição.

Há, no entanto, uma tendência em ambas as respostas de que este tipo de equipamento está presente nas salas de aula e são utilizados em quase todas as circunstâncias. 
Figura 5 - Utilização de aparelhos eletrônicos pelos estudantes (uso orientado)

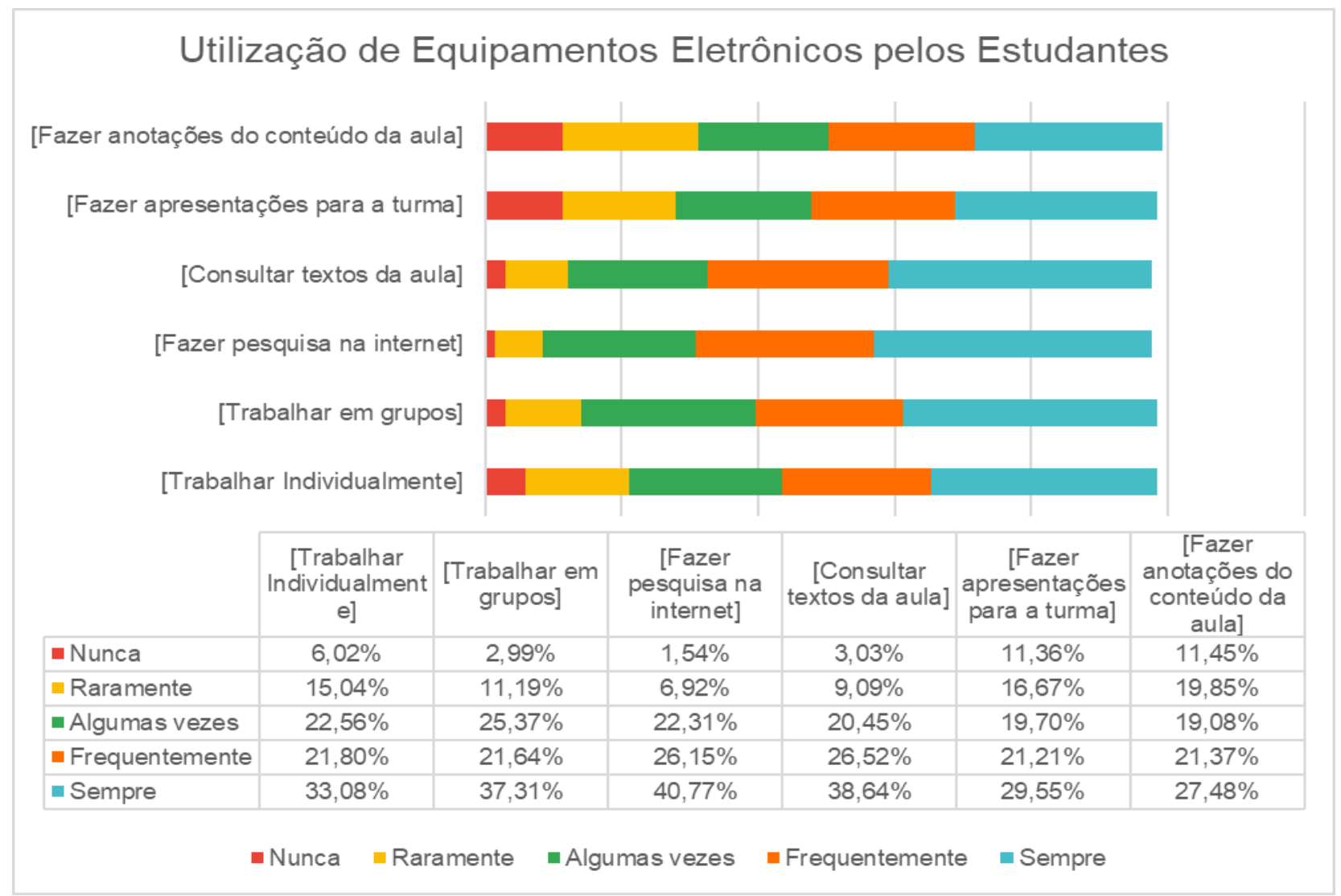

Fonte: Elaborado pelos autores (2019).

\subsection{Percepções sobre o uso de tecnologias}

Dedicou-se um bloco do questionário com o objetivo de medir a percepção dos professores quanto ao uso de tecnologias em sala de aula.

Sobre a obrigatoriedade de se usar tecnologias em sala de aula, 49,62\% concordam que esta prática deveria ser obrigatória, enquanto outros $29,32 \%$ discordam. Para 21,05\% é indiferente a obrigatoriedade ou não.

Para $83,58 \%$ dos entrevistados, o uso de tecnologias em sala de aula motiva os estudantes a aprender, já 7,46\% dos professores não concordam com essa afirmação.

$76,12 \%$ dos professores discordam sobre a assertiva de que a tecnologia diminui a interação entre professor e estudante em sala de aula. Apenas 5,97\% creem neste distanciamento criado pela tecnologia.

$56,30 \%$ dos educadores consideram as tecnologias imprescindíveis para a prática pedagógica em todos os níveis de ensino. Já $22,96 \%$ dos professores entrevistados não concordam com esta condição.

Quanto à afirmação de que "o uso de tecnologia atrapalha as aulas", $84,33 \%$ discordam dela. Apenas $3,73 \%$ dos professores entendem que 0 uso das tecnologias compromete seus encontros com os estudantes.

Para $82,71 \%$ dos professores, o uso de tecnologias estimula o interesse dos estudantes pelos estudos, e 62,69\% não acreditam que as tecnologias desconcentram seus estudantes. 
Embora haja ainda resistência, a crença de que as Tecnologias Digitais de Informação e Comunicação sigam como aliadas ao processo de ensino-aprendizagem, a maioria dos professores entrevistados entendem o papel agregador delas em suas aulas, sobretudo em função do uso recorrente dessas tecnologias no cotidiano de professores a estudantes.

A maioria dos professores entrevistados $(63,91 \%)$ declaram ser motivados por suas instituições de ensino ao uso das tecnologias. 16,54\% declararam não receber estímulo de seus gestores.

$66,42 \%$ dos professores consideram simples incluir as tecnologias digitais no planejamento das suas aulas. Para $16,42 \%$ dos entrevistados, não há simplicidade nesta ação.

$80 \%$ dos entrevistados afirmam usar tecnologias em sala de aula por gostarem deste tipo de ferramenta, e 70,23 disseram que suas aulas ficaram mais atraentes após a opção pelas tecnologias.

Há ainda uma parcela dos entrevistados que demonstra total aversão ao uso de ferramentas tecnológicas em suas aulas, mantendo um perfil estritamente tradicional aos encontros. A maioria, no entanto, é favorável e se sente estimulada ao uso das tecnologias, e percebe, sobretudo, eficácia nessa utilização.

Entretanto, conforme análise dos dados apresentados anteriormente, as tecnologias utilizadas ainda são muito convencionais e conservadoras, o que denota um aproveitamento ainda superficial das TDICs.

\subsection{Ferramentas e estratégias didáticas}

Os docentes responderam sobre quais estratégias didáticas utilizam para a construção de suas aulas. Foram apresentadas a eles uma série de possibilidades que envolvem tecnologia e outras possibilidades que independem de tais recursos. Para facilitar a análise, este questionamento será subdividido nessas duas configurações.

Os docentes entrevistados afirmaram, dentre as estratégias que independem de tecnologia, estimular sempre ou com muita frequência trabalhos em grupos pelos alunos $(74,05 \%)$; discussões em grupo $(66,67 \%)$ e trabalhos individuais para os estudantes $(57,14 \%)$. Apenas $35,11 \%$ afirmam aplicar sempre ou com muita frequência uma aula expositiva sem nenhum tipo de recurso tecnológico. A estratégia mais rejeitada é o júri simulado, nunca aplicada por $58,33 \%$ dos docentes. 
Figura 6 - Ferramentas e estratégias didáticas usadas em sala de aula (sem TDICs)

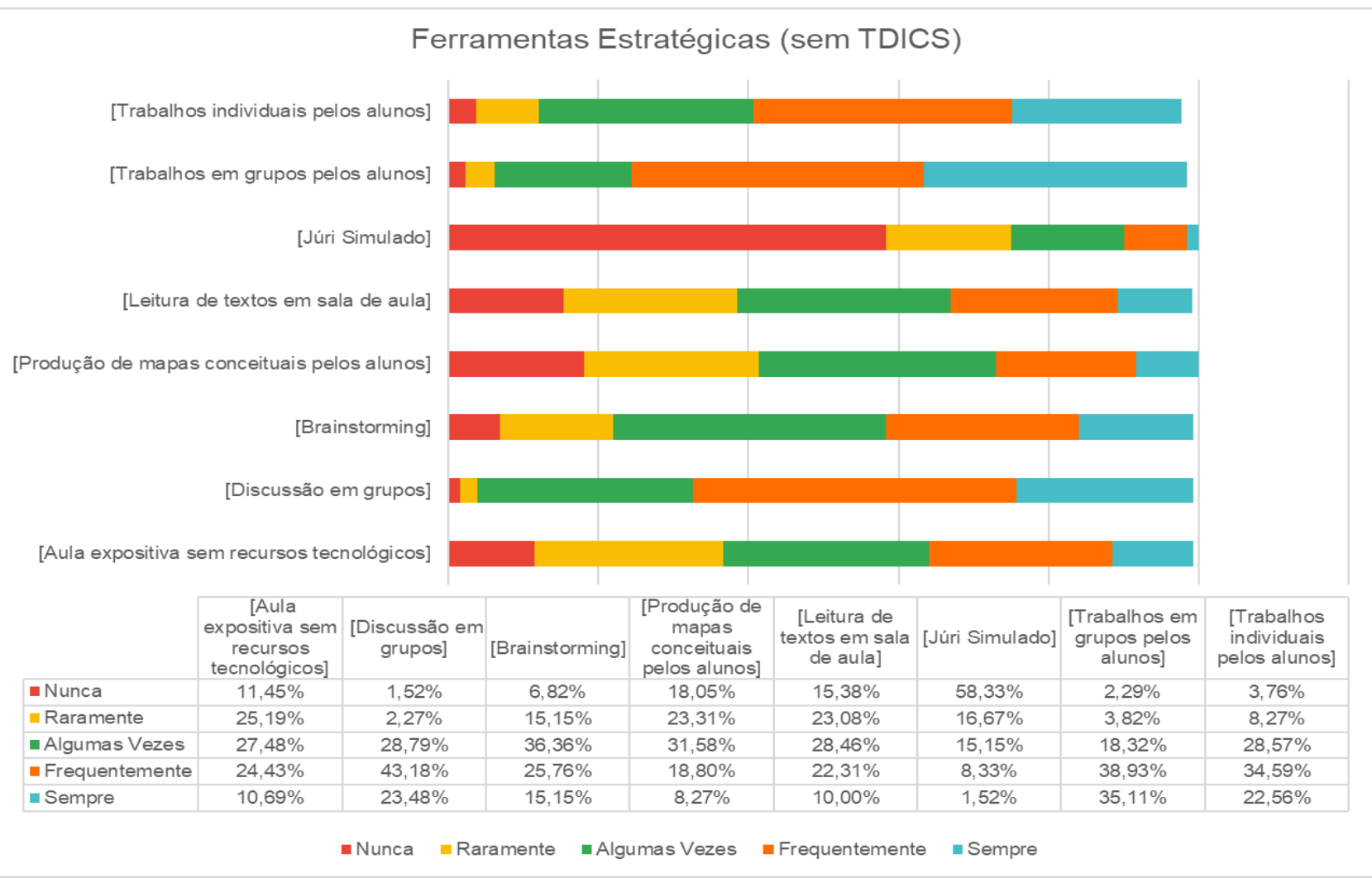

Fonte: Elaborado pelos autores (2019).

A produção de mapas conceituais nunca foi aplicada por $18,05 \%$ dos professores, e outros $23,31 \%$ afirmaram aplicar esse recurso raramente.

Observa-se, por meio dos resultados, o estímulo oferecido pelos professores para que os estudantes se desenvolvam e construam seu conhecimento em pares, por meio de interações em grupo. Algumas estratégias, por serem bem específicas, raramente são utilizadas, caso do júri simulado.

Sobre ferramentas e estratégias aplicadas em sala de aula que utilizam TDICs, obtiveram-se as seguintes percepções: dentre os recursos utilizados sempre ou com muita frequência como meio de aprendizagem em sala de aula pelos docentes, $69,40 \%$ preferem usar notebook, $43,18 \%$ o telefone celular e $17,42 \%$ os tablets. Este último, nunca foi utilizado ou raramente é utilizado nas aulas por $65,15 \%$ dos professores.

$45,04 \%$ dos entrevistados afirmam aplicar sempre, ou com muita frequência, vídeos explicativos em sala de aula; no entanto, apenas $10,61 \%$ dos professores estimulam sua produção por parte dos estudantes. online.

Uma informação significativa é a adesão de $52,31 \%$ dos professores a pesquisas

Quanto aos recursos, se observa uma massiva utilização dos meios mais populares, como notebooks e celulares. Esta percepção se evidencia pela baixa utilização de tablets, corroborada por sua alta rejeição.

Os vídeos são muito bem aceitos nas aulas; no entanto, sua produção é pouco estimulada ainda pelos docentes, o que pode indicar um distanciamento quanto à produção própria de conteúdo, o que já se constatou em resultados apresentados anteriormente. 
Quanto às pesquisas online, muito presentes nas salas de aula dos professores entrevistados, fica o questionamento quanto à curadoria dessas informações e seu bom uso nas aulas.

Quanto às estratégias menos utilizadas pelos docentes, destacam-se a afirmação de "nunca ou raramente ter aplicado a produção de blogs ou sites" (81,06\%), "produção de vídeos com os estudantes" (71,21\%) e "produção de nuvem de palavras" (69,53\%).

Figura 7 - Ferramentas e estratégias didáticas usadas em sala de aula (com TDICs)

\section{Ferramentas e Estratégias (com TDICS)}

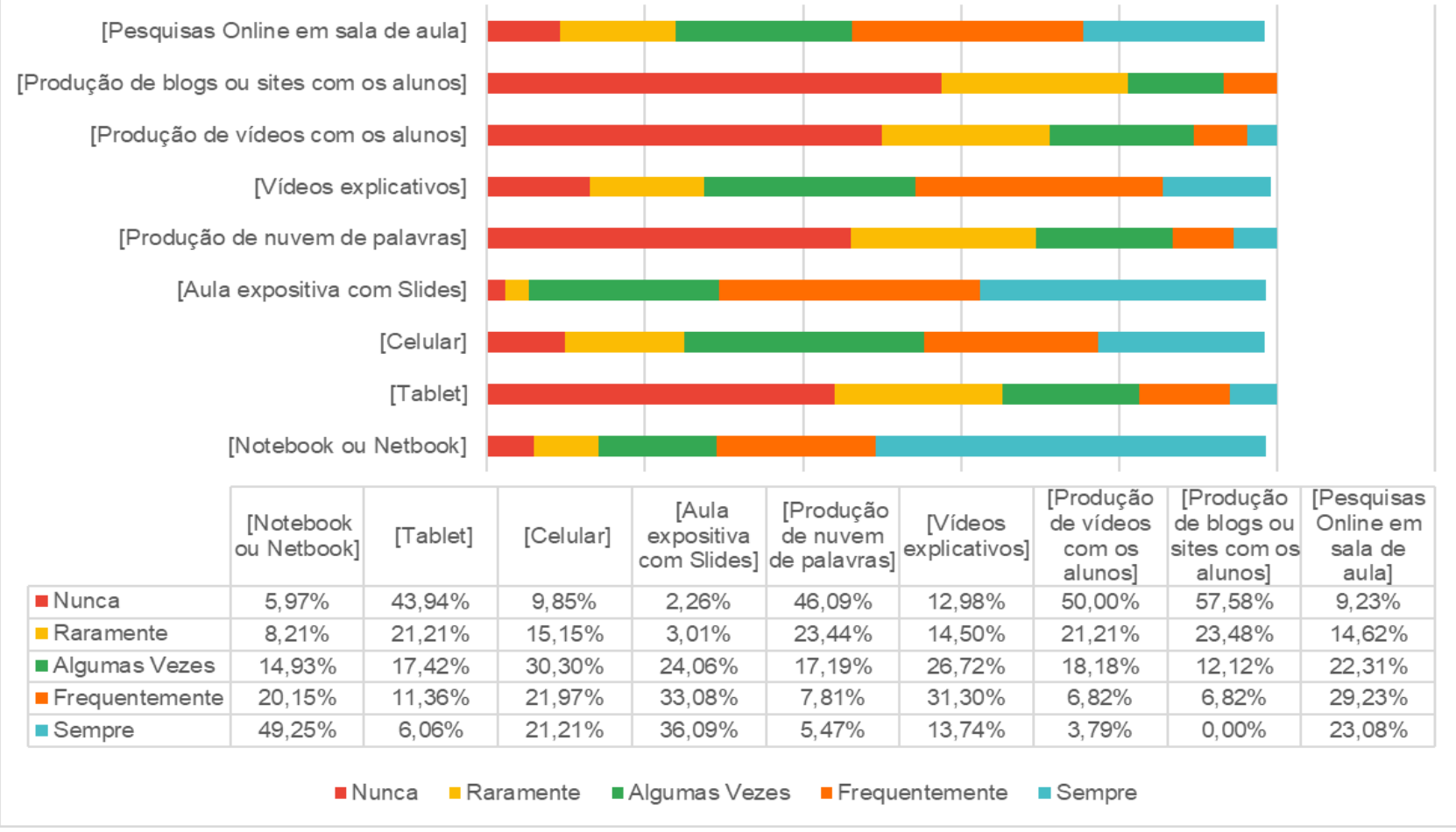

Fonte: Elaborado pelos autores (2019)

Ratifica-se, com os dados acima, o pouco aproveitamento das tecnologias como estímulo e produção do conhecimento, por meio de textos, vídeos e áudios por parte dos professores e estudantes.

\subsection{Percepções sobre o uso de tecnologia e inovação}

Neste bloco, coletaram-se as percepções dos docentes sobre o uso de tecnologia em sala de aula e o potencial desta utilização para a criação de espaços de aprendizagem mais inovadores.

Para $62,41 \%$ dos docentes entrevistados, a integração das tecnologias do ensino superior garante a inovação, opinião contrária de $18,05 \%$ dos entrevistados. Ainda nesta temática, para 59,85\% dos professores, a infraestrutura tecnológica educacional garante a inovação na educação superior, pensamento diferente de $18,18 \%$ dos professores.

Este resultado indica que a maioria dos professores relaciona as ferramentas tecnológicas e seus benefícios à inovação na educação superior.

No entanto, há uma divisão quanto à substituição completa de práticas educacionais classificadas como "tradicionais" por aquelas que se fazem valer de recursos inovadores. 36,92\% dos professores afirmaram que a inovação nas práticas educacionais indica a ruptura com as práticas anteriores; contudo, $40 \%$ dos entrevistados discordam desta afirmação, o que nos impele a acreditar que se vive um cenário híbrido, 
ainda em modificação, ou seja, uma transição entre os modelos tradicional e práticas inovadoras.

Um dos professores entrevistados fez o seguinte comentário ao relacionar a tecnologia à inovação no cenário educacional: "a inovação independente da tecnologia. Devemos inovar sempre em nossas aulas criando mecanismos de interação entre professores e alunos de modo que os alunos se interessem em participar das atividades independentemente da tecnologia que possa estar sendo utilizada".

Outro entrevistado relacionou inovação a uma finalidade: "significa traduzir o conteúdo a ser desenvolvido em uma linguagem atual e estimulante para um grupo de alunos específico. A inovação da prática deve ocorrer com a intenção primeira de disseminar o conhecimento, e não com vistas a resultar em uma aula espetáculo".

Quanto ao perfil dos docentes e sua relação com ou uso de tecnologias e a construção de um cenário educacional inovador, 52,67\% dos entrevistados afirmam que para se promover práticas inovadoras, a formação do professor é fator determinante, e a inovação das práticas depende da experiência prévia com o uso de tecnologias desses profissionais $(63,85 \%)$.

Contudo, atributos como a idade ou o tempo de formação do professor não são considerados relevantes. Para $62,22 \%$, a inovação das práticas independe da idade do professor, e $66,41 \%$ afirmam que as práticas inovadoras independem do tempo de experiência do professor no magistério.

Os professores acreditam que a inovação no ambiente educacional é impulsionada por fatores externos, seja pelo contexto social e cultural $(71,32 \%)$, pelos próprios colegas de trabalho $(66,15 \%)$ ou pelos próprios estudantes $(63,36 \%)$.

A maioria dos docentes entrevistados (80,77\%) afirma que em um cenário educacional inovador é necessário que se pressuponha que o professor passe a assumir o papel de mediador, ou seja, um facilitador na construção do conhecimento. Esta afirmação indica que os docentes se preocupam com a facilidade ao acesso às informações e tentam estabelecer uma curadoria com os estudantes, indicando os melhores caminhos e identificando as informações mais úteis.

\subsection{Percepções sobre ações consideradas inovadoras}

Os professores entrevistados responderam sobre ações que consideram inovadoras e que podem ser aplicadas em suas aulas.

As ações consideradas mais inovadoras pelos professores são aquelas relacionadas à produção de conteúdo, dentre as quais destacam-se: criação de podcast pelos estudantes $(66,92 \%)$, criação de textos colaborativos online $(66,17 \%)$ e produção de blogs e sites $(62,88 \%)$.

Os resultados analisados anteriormente indicam que justamente estas atividades são as mais desafiadoras e menos utilizadas pelos professores em suas aulas.

A criação de grupos de comunicação em aplicativos como WhatsApp e Facebook não são práticas consideradas inovadoras na opinião dos professores. Este último, inclusive, contou com alta rejeição à sua utilização, conforme resultados analisados anteriormente.

A exibição de vídeos não é considerada uma ação inovadora na percepção de $38,81 \%$ dos professores, assim como realizar trabalhos em grupo com os alunos, conforme a opinião de $36,06 \%$ dos entrevistados. Estas atividades, consideradas pouco 
inovadoras, convergem com as mais praticadas pelos professores, conforme resultados já analisados.

\section{CONSIDERAÇÕES FINAIS}

As novas tecnologias criaram espaços alternativos para a construção do conhecimento. Nos dias atuais, além da escola, também a empresa, o espaço domiciliar e o espaço social tornaram-se educativos. A cada dia, mais pessoas estudam remotamente, pois podem acessar o ciberespaço de formação e da aprendizagem e buscar informações disponíveis nas redes de computadores interligados e serviços que respondem às suas demandas de conhecimento.

Corroborando esta percepção, a sociedade civil está se fortalecendo não apenas como espaço de trabalho, em muitos casos voluntário, mas também como espaço de difusão de conhecimentos e de formação continuada. É um espaço potencializado pelas novas tecnologias, inovando constantemente nas metodologias.

Novas oportunidades parecem se abrir para os educadores. Esses espaços de formação têm tudo para permitir maior democratização da informação e do conhecimento; portanto, menos distorção e menos manipulação, menos controle e mais liberdade.

Um dos principais entraves da aprendizagem está na dificuldade em ser interessante ao público-alvo, decorrente de um descompasso temporal entre os integrantes do universo pedagógico: escola, professores e estudantes. Enquanto os estudantes do século XXI representam a geração multitarefa, ou seja, são capazes de executar duas ou mais atividades ao mesmo tempo, as escolas, em sua maioria, ainda estão presas a uma estrutura do século XIX, uma vez que muitas não possuem laboratório de tecnologia ou internet banda larga, são equipadas com móveis pesados e alunos dispostos em fileiras na constituição das salas de aula.

Este trabalho alcança o seu propósito principal ao propiciar reflexões acerca da utilização das tecnologias da informação e comunicação como ferramentas no processo ensino-aprendizagem no ensino superior, valendo-se do levantamento e demonstração das principais aplicações disponíveis e utilizáveis a serviço do cenário educacional e sua efetiva aplicação pelos educadores, seja no ensino presencial ou ensino a distância.

Dentre as principais reflexões, foram alcançadas as seguintes conclusões: o educador dos dias atuais entende a importância da utilização de recursos tecnológicos em seus encontros e enxerga uma relação importante entre estes recursos e a inovação; no entanto, ainda os aplica de forma tímida, dando preferência a ferramentas mais formais e populares.

O uso de computadores, celulares, tablets ou equipamentos de projeção nutridos por elementos lógicos comuns para finalidades conhecidas não necessariamente implica inovação, pois estes recursos já estão presentes no dia a dia de estudantes e professores. Não se aplica nada de diferente ao se usar essas ferramentas de forma usual.

As ferramentas digitais com a capacidade de produzir e armazenar conteúdo construído de forma autônoma, como construção de sites, blogs, vídeos e podcasts são utilizados com muita pouca frequência, o que nos leva a inferir que há um subaproveitamento da prática de produção de conteúdo, de forma colaborativa e compartilhada. 
O estudo mostra que muitas práticas educacionais atuais ainda se aproximam de modelos tradicionais de ensino, enxertados com momentos de interação entre os estudantes e professores e ilustrados com práticas já incorporadas ao nosso cotidiano, como vídeos, imagens e troca de documentos online.

É importante que o educador reconheça que a sociedade atual vem exigindo, cada vez mais, um conhecimento mais abrangente a respeito das TDICs. Isso se torna possível por meio da formação inicial e continuada desse profissional, que assegure uma compreensão significativa desses novos instrumentos pedagógicos, reconhecendo as modificações que as novas tecnologias provocam nos processos de aprendizagem.

Este estudo ratifica o problema de pesquisa levantado, ou seja, mesmo havendo professores e tutores engajados no uso de tecnologias em suas aulas, este esforço se perde em meio a um conjunto de ações pedagógicas desarticuladas que não se consegue traduzir em ações, por uma deficiência de sinergia coletiva.

\section{REFERÊNCIAS}

ABED - Associação Brasileira de Educação a Distância. Disponível em: http://www.abed.org.br/site/pt/ - 2009 A 2013. Acesso em: 07 out.2019.

ANPED. Associação Nacional Pós-Graduação e Pesquisa em Educação. CD-ROM. São Paulo, 1996.

ANPED. Associação Nacional Pós-Graduação e Pesquisa em Educação. São Paulo, 2011-2013. Disponível em: http://www.anped.org.br/. Acesso em: 07 out. 2019.

BARDIN, L. Análise de Conteúdo. Tradução de Luis Antero Reto e Augusto Pinheiro. Lisboa, Edições 70, 2006.

BATISTA, E. M e GOBARA, S. T. Interação na pedagogia a distância de uma instituição pública brasileira. Revista Interações, n. 37, pp.124-149. (2015). Disponível em: http://revistas.rcaap.pt/interaccoes/article/view/8469/6044. Acesso em: 07 out. 2019.

CHAUÍ, M. A universidade operacional. Revista da ADUNICAMP, Campinas, ano 1, n.1, jun. de 1999.

FONSECA, S.M; NETO, J.A.M. Metodologias ativas aplicadas à educação a distância: revisão de literatura. Revista Edapeci, São Cristóvão (SE), v.17. n. 2, p. 185-197. mai/ago. 2017. Disponível em:

https://seer.ufs.br/index.php/edapeci/article/download/6509/pdf. Acesso em: 07 out. 2019.

FREIRE, P. A educação na cidade. 5. ed. São Paulo: Cortez, 2001.

FREITAS, M. T. A. Tecnologias digitais: cognição e aprendizagem. In: REUNIÃO NACIONAL DA ANPED, 37., 2015. Anais... Florianópolis, 2015. UFSC, Florianópolis.

GÓIS, R. P. Q. de R.; RIZZARDO; SANTOS, G. M. M. dos; FELISBERTO, P. O.; SILVA, A. M. da; CARVALHO, L. C. de. Tecnologias da informação e comunicação no ensino superior e seus benefícios. CIET:EnPED, [S.I.], maio 2018. Disponível em: https://cietenped.ufscar.br/submissao/index.php/2018/article/view/502. Acesso em: 07 out. 2019. 
LIMA, J. As Novas Tecnologias no Ensino. 2006. Disponível, em:

http://www.airpower.au.af.mil/apinternational/apjp/2006/2tri06/lima.html. Acesso em: 07. out. 2019.

MÉSZÁROS, I. A educação para além do capital. São Paulo: Boitempo, 2008.

MOMO, F.S.; BEHR, A.; MARCOLIN, C. B.; FARIAS, E. da S. Um Diagnóstico do uso das Tecnologias da Informação e Comunicação (TICs) em uma Instituição de Ensino Superior. Revista de empreendedorismo, educação e tecnologia, Rio grande do Sul, v.4, n.2, 2017.Disponível em: https://seer.imed.edu.br/index.php/revistasi/article/view/2085/1711. Acesso em: 07 out.2019.

MORAN, J. O que é educação a distância. Disponível em: http://www2.eca.usp.br/moran/wp-content/uploads/2013/12/dist.pdf. Acesso em: 07 out.2019.

MOREIRA, J. A.; MONTEIRO, A. O trabalho pedagógico em cenários presenciais e virtuais no ensino superior. Educação, Formação e Tecnologias. v. 3, n. 2, p. 82-94, 2010. Disponível em: http://eft.educom.pt/index.php/eft/ article/viewFile/173/117. Acesso em: 07 out. 2019.

NEVES, C. M. A Educação a Distância e a Formação de Professores. In: ALMEIDA, E. B.; MORAN, J. M. (Orgs). Integração das Tecnologias na Educação. Brasília: Secretaria de Educação a Distância - SEED/MEC, 2005.

RAMAL, A. C. Educação a distância: entre mitos e desafios. In: ALVES, L.;

NOVA, C. (Org.). Educação a distância: uma nova concepção de aprendizado e interatividade. São Paulo: Futura, 2003. p. 43-50.

SEVERINO, A. J. Metodologia do trabalho científico. São Paulo: Cortez \& Moraes, 1976.

SILVA, A. E. D. C.; COUTO, E. S. Professores que usam smartphones: Considerações sobre tecnologias móveis em práticas docentes. In: 37ª REUNIÃO NACIONAL DA ANPED, 36., 2013. Anais... Goiânia, 2013. Disponível em:

http://36reuniao.anped.org.br/pdfs_trabalhos_aprovados/gt16_trabalhos_pdfs/gt16_2663_t exto.pdf. Acesso em: 07 out. 2019.

SILVA, F. D. de O. O professor frente as novas tecnologias e as implicações no trabalho docente. In: CONEDU - CONSELHO NACIONAL DE EDUCAÇÃO, 3, 2016. Anais... Natal, 05-07 out. 2016. Disponível em:

http://www.editorarealize.com.br/revistas/conedu/trabalhos/TRABALHO_EV056_MD1_SA 19_ID4989_19082016035853.pdf. Acesso em 07 out.2019.

TARCIA, R. M. L.; COSTA, S. M. C. Contexto da educação a distância. In: CARLINI, A. L.; TARCIA, R. M. L. $\mathbf{2 0 \%}$ a distância e agora? orientações práticas para o uso de tecnologia de educação a distância no ensino presencial. São Paulo: Pearson Education do Brasil, 2010.

VYGOTSKY, L. S. Psicologia Pedagógica. Edição comentada. Tradução de Cláudia Shilling. São Paulo: Artmed, 2003.

VYGOTSKY, L. S. A Formação Social da Mente. São Paulo: Martins Fontes, 1984. 